\title{
Reforma del edificio principal de la Quinta La Vega para vivero de empresas
}

\author{
ARQUITECTOS \\ Marcos Gómez Sastre - Z2arquitectos \\ Marina Gil Alonso- Estudio de arquitectura FabricArq \\ PROMOTOR \\ IMPULSA Centro Municipal de Empresas de Gijón, S.A. \\ CONSTRUCTORA \\ El Corte Inglés, S.A. \\ FOTOGRAFIAS \\ Jorge Allende - Fotografía de Arquitectura \\ Z2arquitectos
}

\section{RESUMEN:}

El proyecto ejecutado consiste en la reforma del edificio principal de la "Quinta la Vega", situado en Jove, Gijón. El proyecto de intervención es totalmente respetuoso con el edificio existente en lo que a su configuración exterior se refiere. No se actúa sobre las fachadas ni sobre la cubierta y, por lo tanto, no se altera la volumetría existente. Las intervenciones exteriores serán exclusivamente de restauración y mantenimiento de las carpinterías, galerías, barandillas y balaustradas existentes. Las obras realizadas se centran en una serie de actuaciones interiores para reformar el edificio principal, con el fin de adecuarlo a su nuevo uso como vivero de empresas.

\section{PALABRAS CLAVE:}

Reforma, quinta, Jove, oficina, celosía.

ABSTRACT:

The project implemented consists in reforming the main building of the "Quinta la Vega", located in Jove, Gijon.The intervention project fully respects the existing building in terms of its external configuration. No work will be carried out on the façades or on the roofing; therefore the existing volumetrics will not be altered. External actions will be strictly limited to restoring and maintaining the carpentry, arcades, railings and balustrades already in place. The works carried out are based on a series of interior actions to reform the main building, with the aim of adapting it for its new use as a business incubator.

\section{KEY WORDS:}

Reform, quinta, Jove, office, lattice. 


\section{Emplazamiento}

El edificio objeto del proyecto está dentro de la antigua finca conocida como "Quinta la Vega" o "Casa de Nava", situada junto a la Iglesia de Jove, en el mismo lugar donde anteriormente hubo una villa romana.

Este enclave privilegiado da cuenta de la importancia del lugar, en un momento en el que la parroquia de Jove era una de las ubicaciones más atractivas de Gijón, elegida por la burguesía de finales del siglo XIX como zona residencial y de recreo, debido a sus privilegiadas vistas de la costa y de la ciudad.

\section{Historia del edificio}

Al mismo tiempo que se produce la ocupación y crecimiento del barrio de Somió, con edificaciones de vivienda unifamiliar construidas por la burguesía gijonesa, tiene lugar el mismo proceso en el barrio de Jove, otra zona rural con playa en su costa situada al oeste de la ciudad, pero distanciada del barrio obrero de la Calzada.
El edificio conocido como Quinta la Vega o Bordiú fue construido hacia 1890, con una tipología repetida en otras casas similares de este período. Se caracteriza por su volumen prismático con cubierta a dos aguas, una ordenada distribución de los huecos y una abigarrada decoración en sus aleros. Como elemento singular se adosa a este sencillo volumen una terraza sostenida sobre esbeltos pilares de fundición.

El barrio mantuvo su estatus residencial de calidad hasta mediados del siglo XX, momento en que la degradación de su entorno (desaparición de las playas, aumento de superficie del puerto del Musel e implantación de vivienda obrera) hizo poco atractivo el lugar, siendo las grandes residencias demolidas o abandonadas durante largo tiempo como fue el caso de esta Quinta.

En 2001 se lleva a cabo una rehabilitación del edificio principal y del edificio de las antiguas caballerizas de la Quinta la Vega, realizada por los arquitectos Juan González Moriyón y Javier Hernández Cabezudo para la Autoridad Portuaria de Gijón.

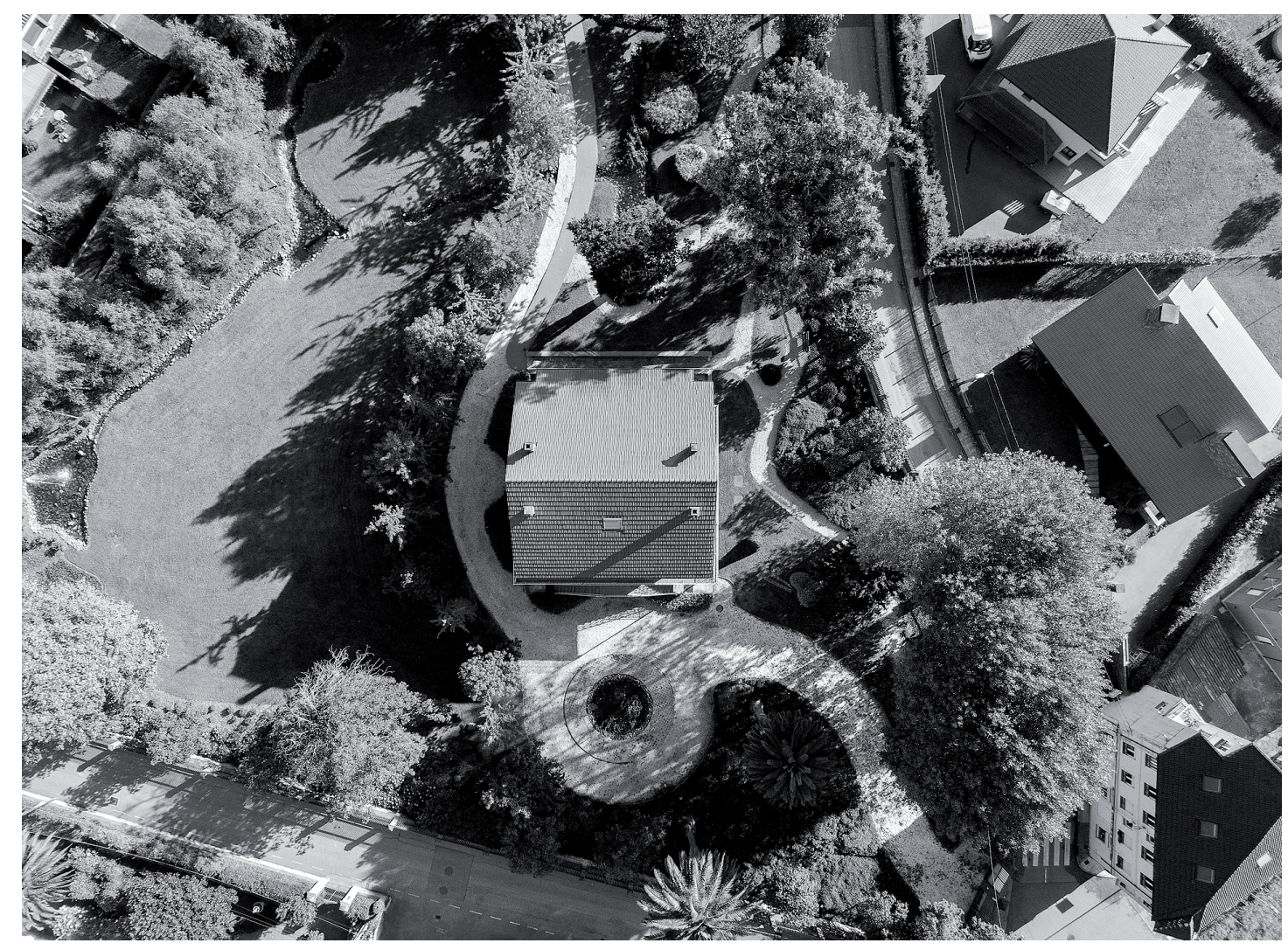

Figura 1. Imagen aérea del edificio principal y del jardín. 

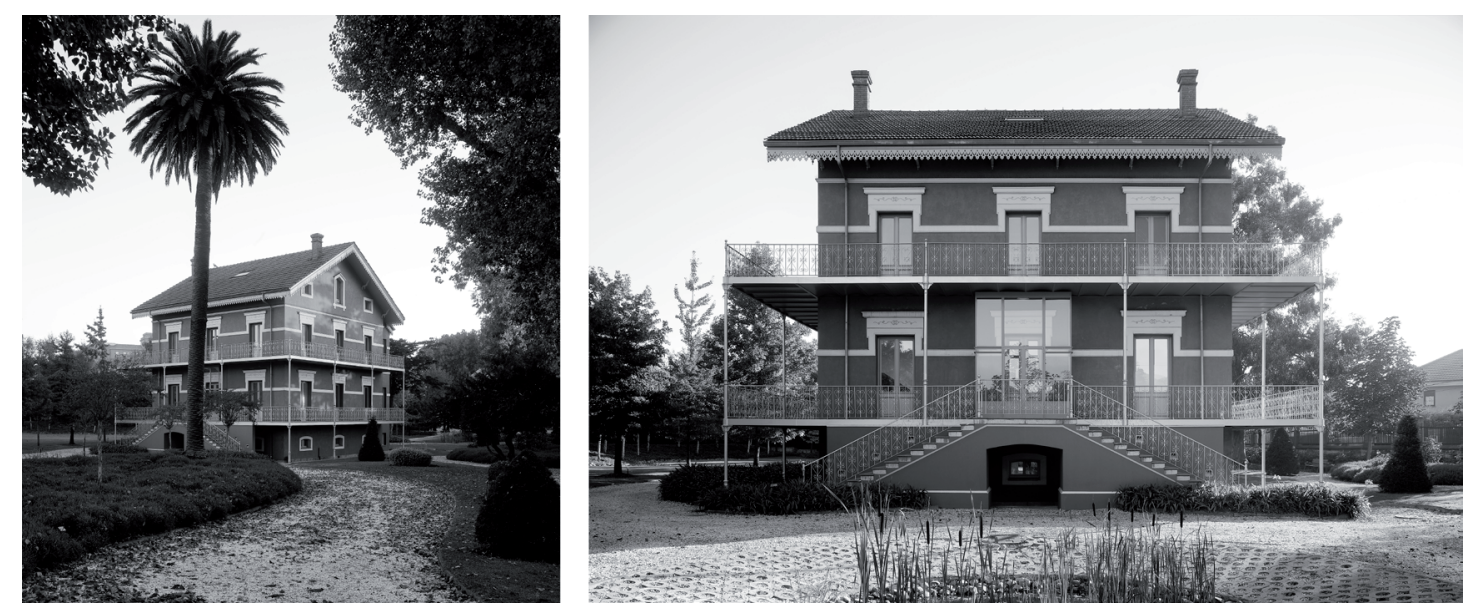

Figura 2. Vistas exteriores del edificio principal
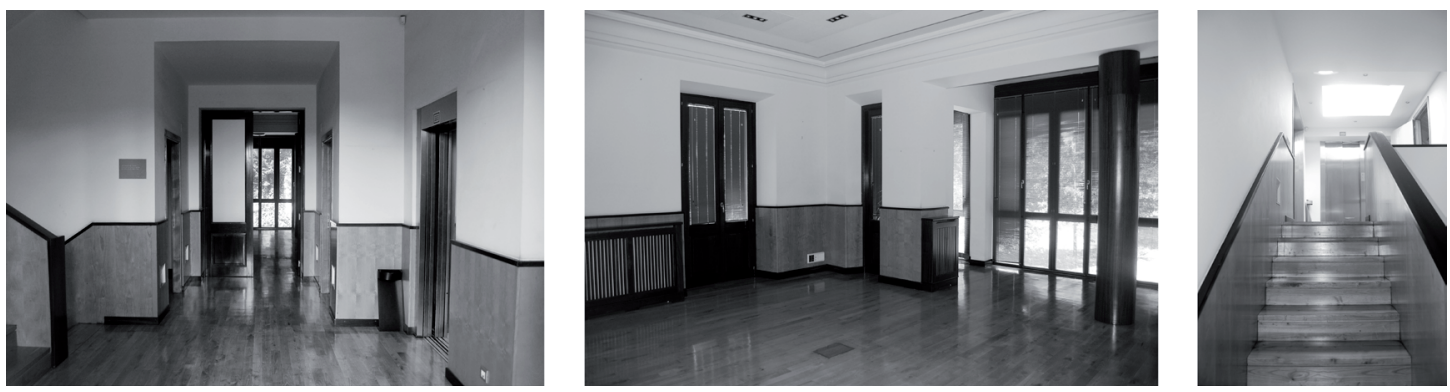

Figura 3. Vistas interiores (año 2016). Estado anterior a la reforma.

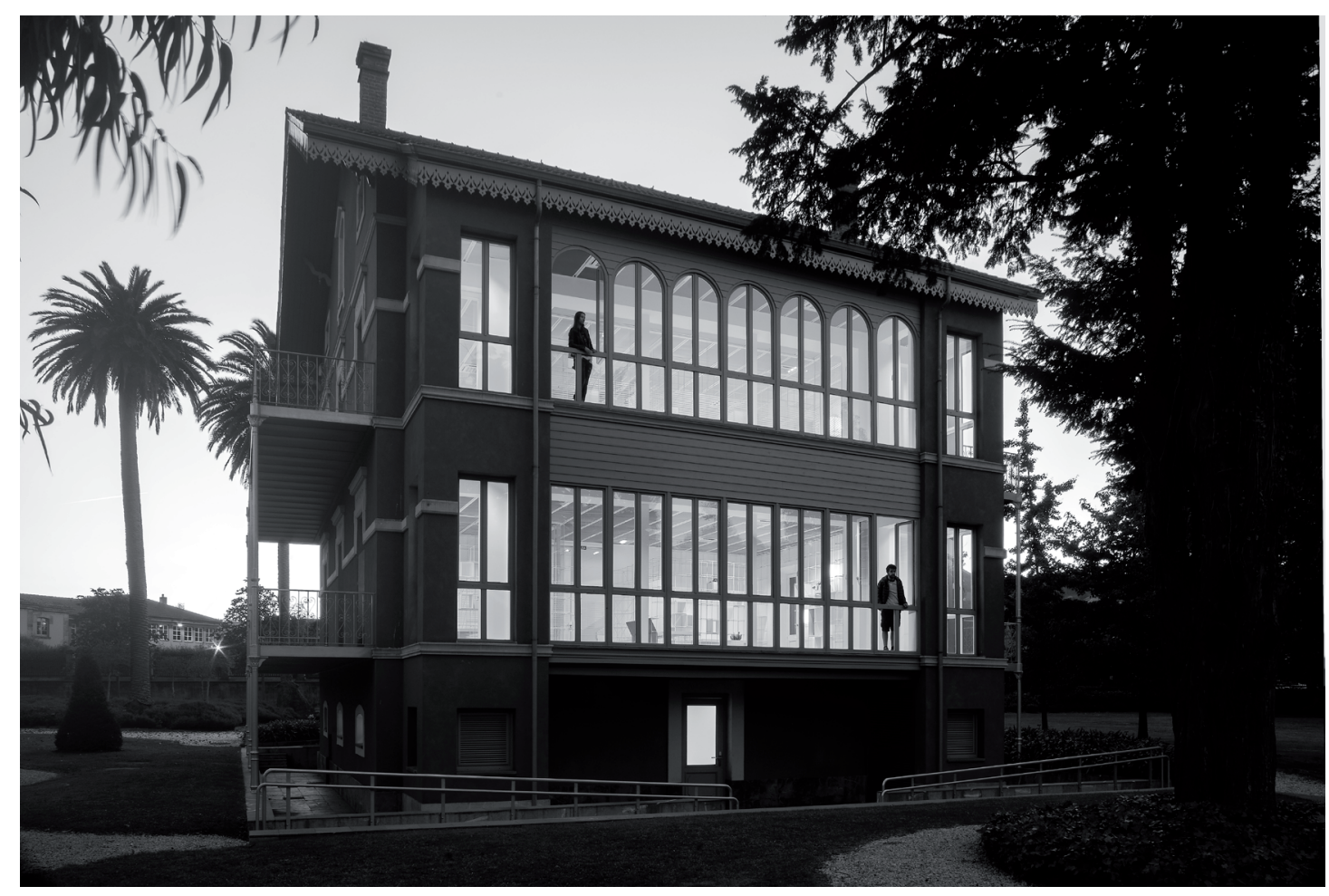

Figura 4. Vista exterior. Galería tras la intervención. 


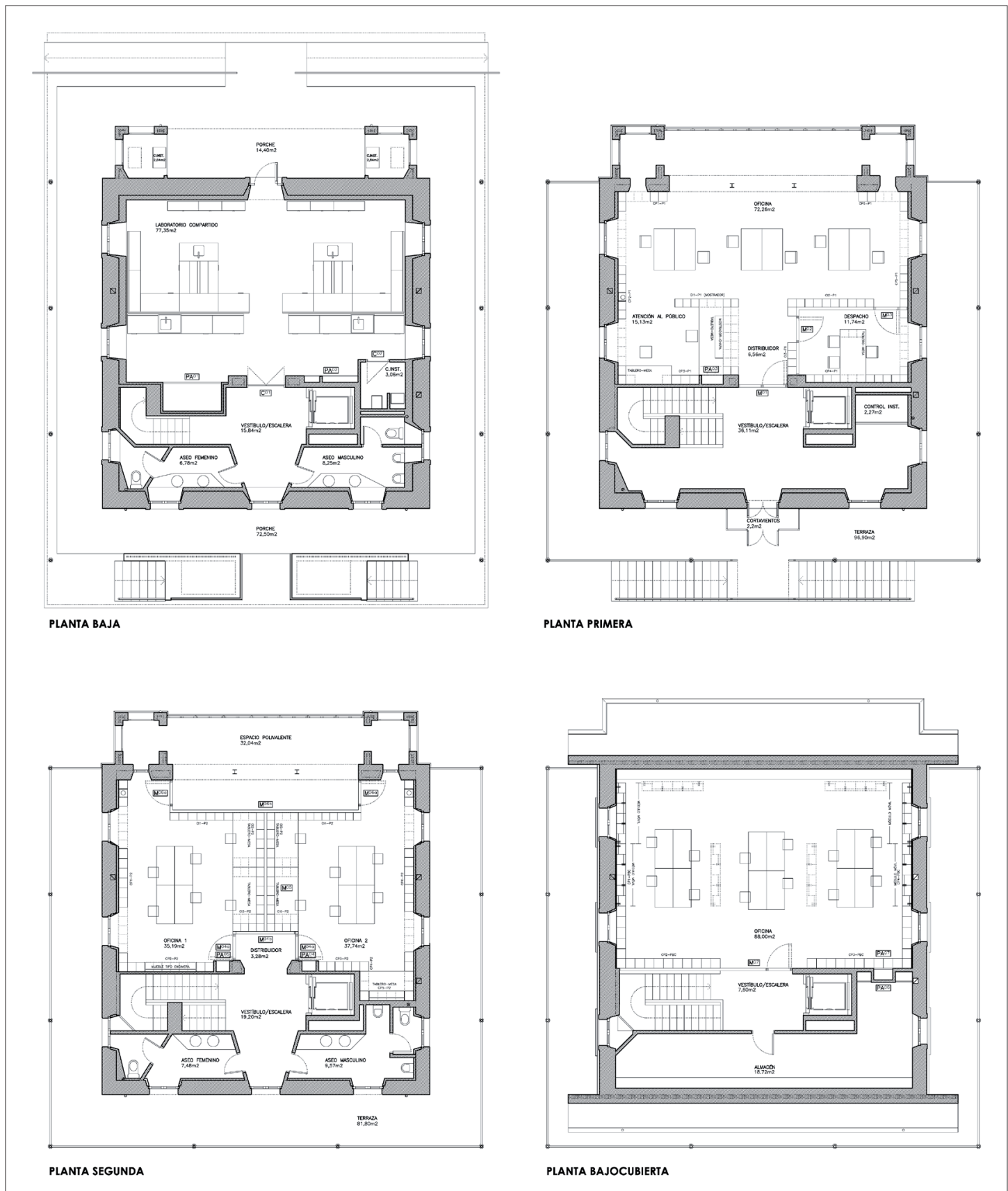

Figura 5. Plantas de los 4 niveles tras la intervención.

\section{Objetivo de la intervención}

En 2016, el Ayuntamiento de Gijón decide adquirir el conjunto inmobiliario que compone la denominada "Quinta la Vega", propiedad de la Autoridad Portuaria. Se trata de un edificio protegido por el Plan General de Ordenación Urbana, que está incluido dentro del Catálogo Urbanístico, con un grado de protección integral. Además, el jardín de la finca también cuenta con protección.
El complejo pasa a estar gestionado por el Centro Municipal de Empresas de Gijón, quien decide dar un nuevo uso al edificio creando un vivero de empresas cuyas actividades giren en torno a la vida saludable, sostenible y relacionadas con el medio ambiente.

De esta manera, se decide que las tres plantas superiores del edificio pasen a convertirse en espacios de oficinas para su alquiler, mientras que en la planta baja se disponga un laboratorio de uso compartido. 


\section{Diseño}

El actual edificio principal de la Quinta la Vega consta de cuatro plantas y tiene una estructura compositiva muy clara, en la que el núcleo de comunicación vertical y las zonas de vestíbulos y baños marcan el esquema de organización.
La propuesta de reforma que afronta el proyecto mantiene intacta esa distribución en todas las plantas, respetando la esencia del edificio original. Tan solo se buscan nuevas distribuciones en las zonas vinculadas a las galerías de las plantas nobles, jugando con transparencias que permitan la mayor apertura visual posible.

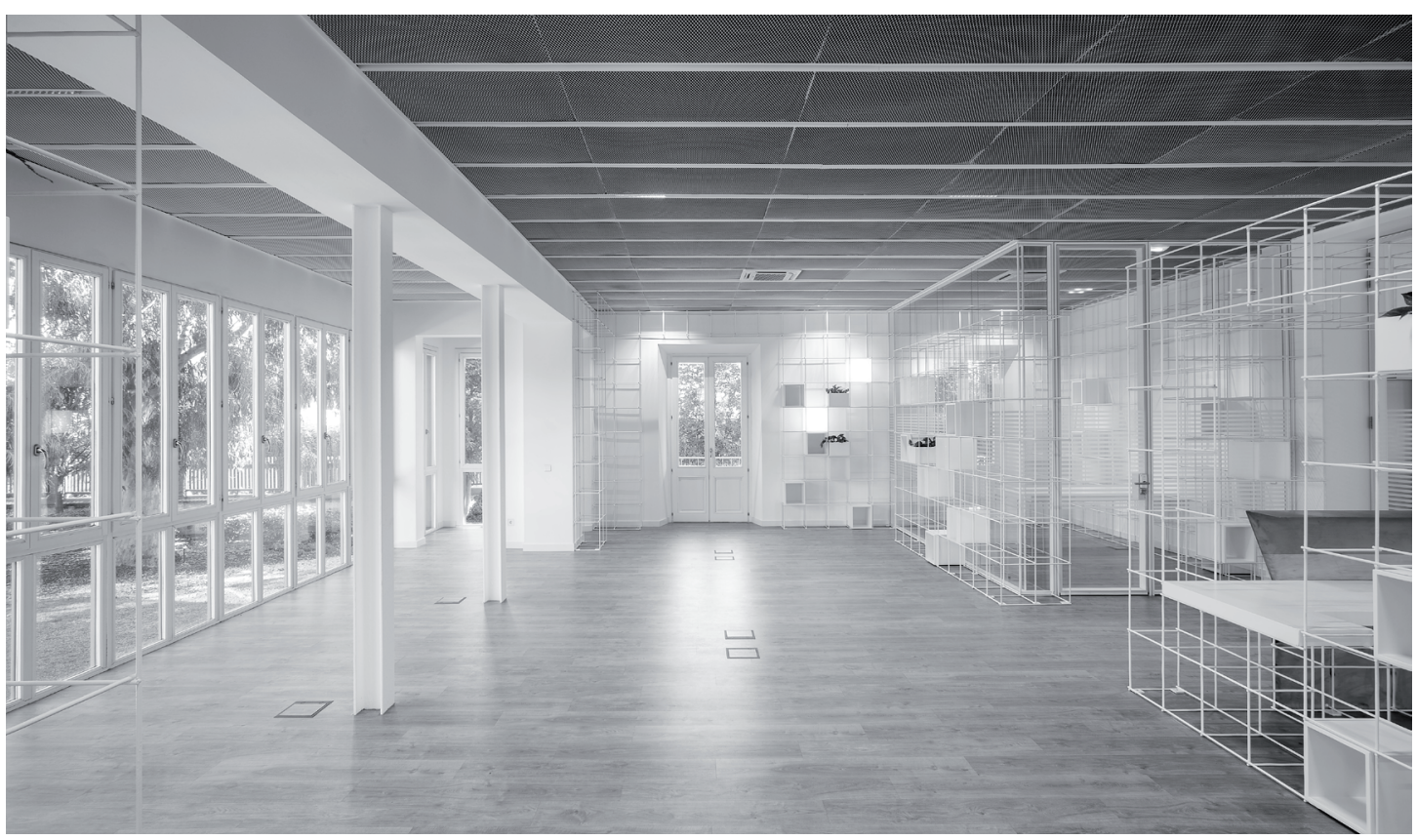

Figura 6. Vista del espacio principal en planta primera.

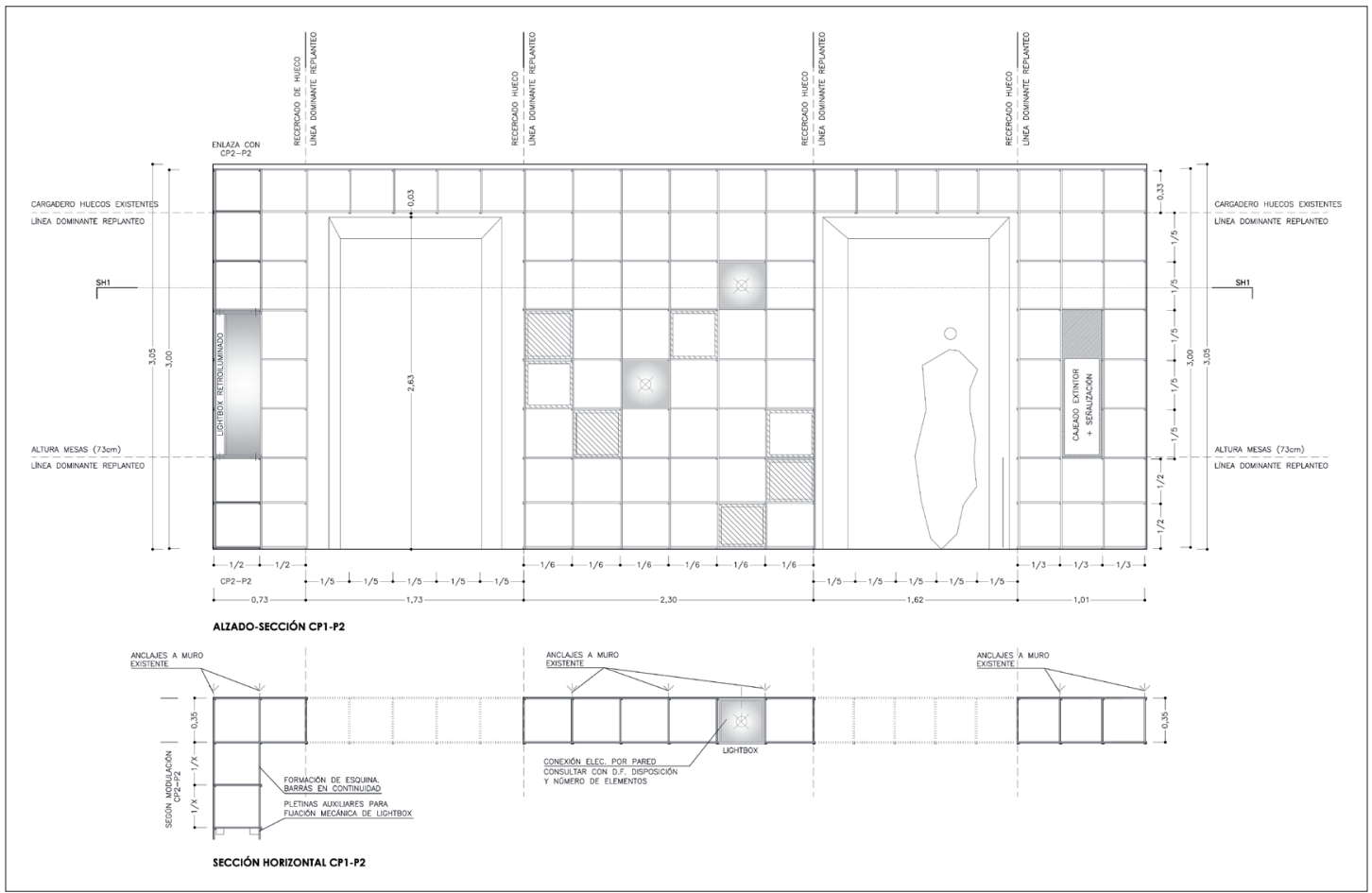

Figura 7. Detalles de celosía. Integración de luminarias y mobiliario. 
El motivo generador del proyecto va íntimamente asociado a la construcción de una malla tridimensional de redondos de acero, que servirá para potenciar las divisiones de las distintas estancias previstas, sin llegar a fragmentar visualmente el espacio, y permitiendo en todo momento el paso de la luz a través de ellas. Se trata de un elemento mixto, a medio camino entre una celosía y un tipo de mobiliario fijo hecho a medida.

La malla se adaptará a las necesidades funcionales de cada zona del edificio y ayudará a componer espacios mediante la construcción de pórticos, puentes, o particiones tipo celosía. Dentro de esta malla, se introducirán distintos elementos de almacenaje, iluminación y vege- tación, mediante un sistema de "cajas" que se adaptan a la modulación.

\section{Actuaciones a realizar}

Descripción de las intervenciones por plantas:

\section{- Planta Baja:}

Se respetan los baños y las zonas de circulación. A partir de estos espacios comunes se plantea la demolición de las dos estancias simétricas que aparecen vinculadas a los huecos con el fin de crear un único espacio diáfano que sirva de laboratorio común. Se readapta además la distribución del cuarto de instalaciones.

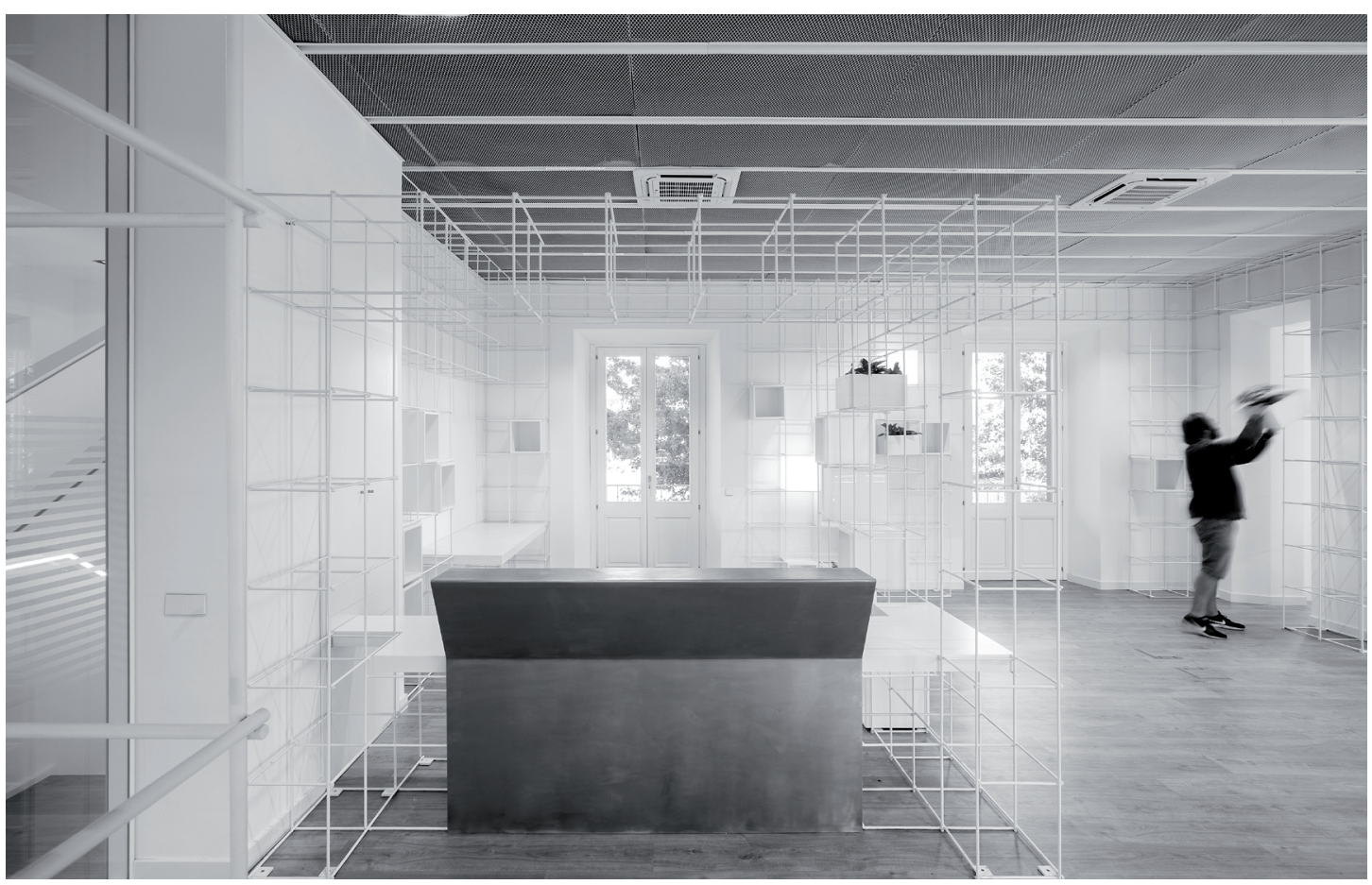

Figura 8. Vista interior de planta primera y detalle de mostrador.
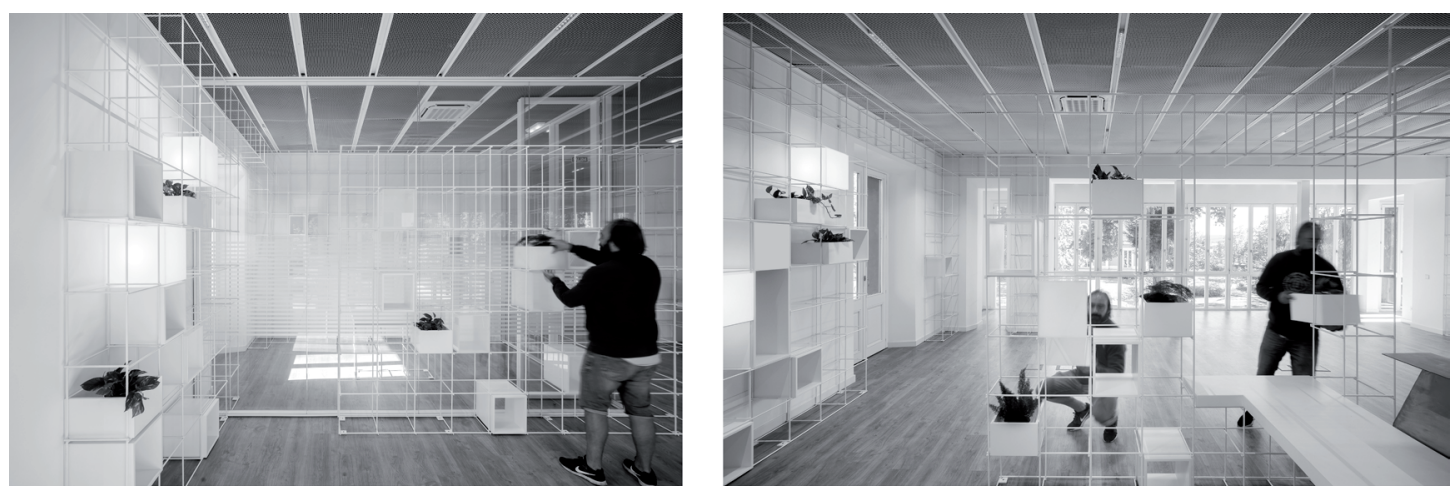

Figura 9. Vistas interiores de planta primera. Detalles de malla. 

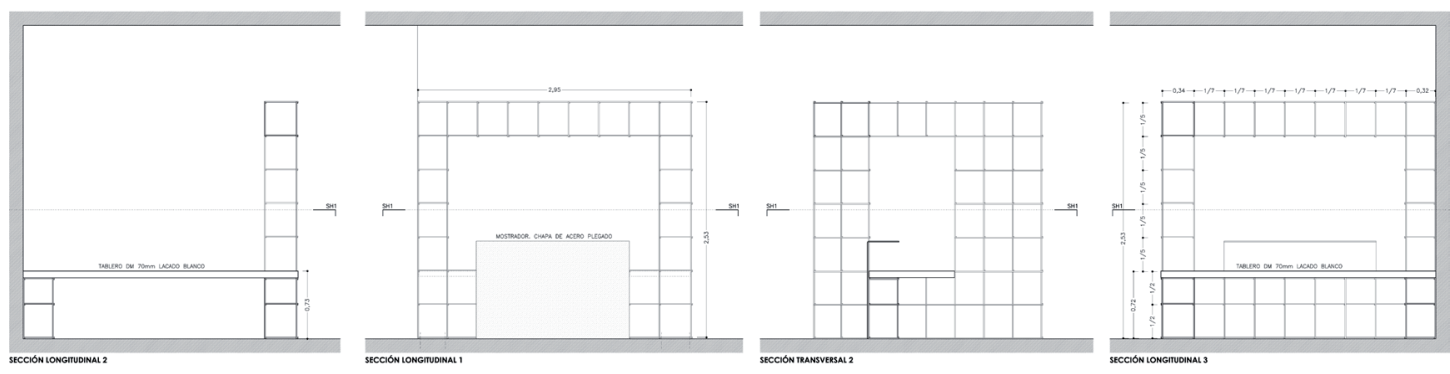

Figura 10. Detalles constructivos de malla tridimensional.

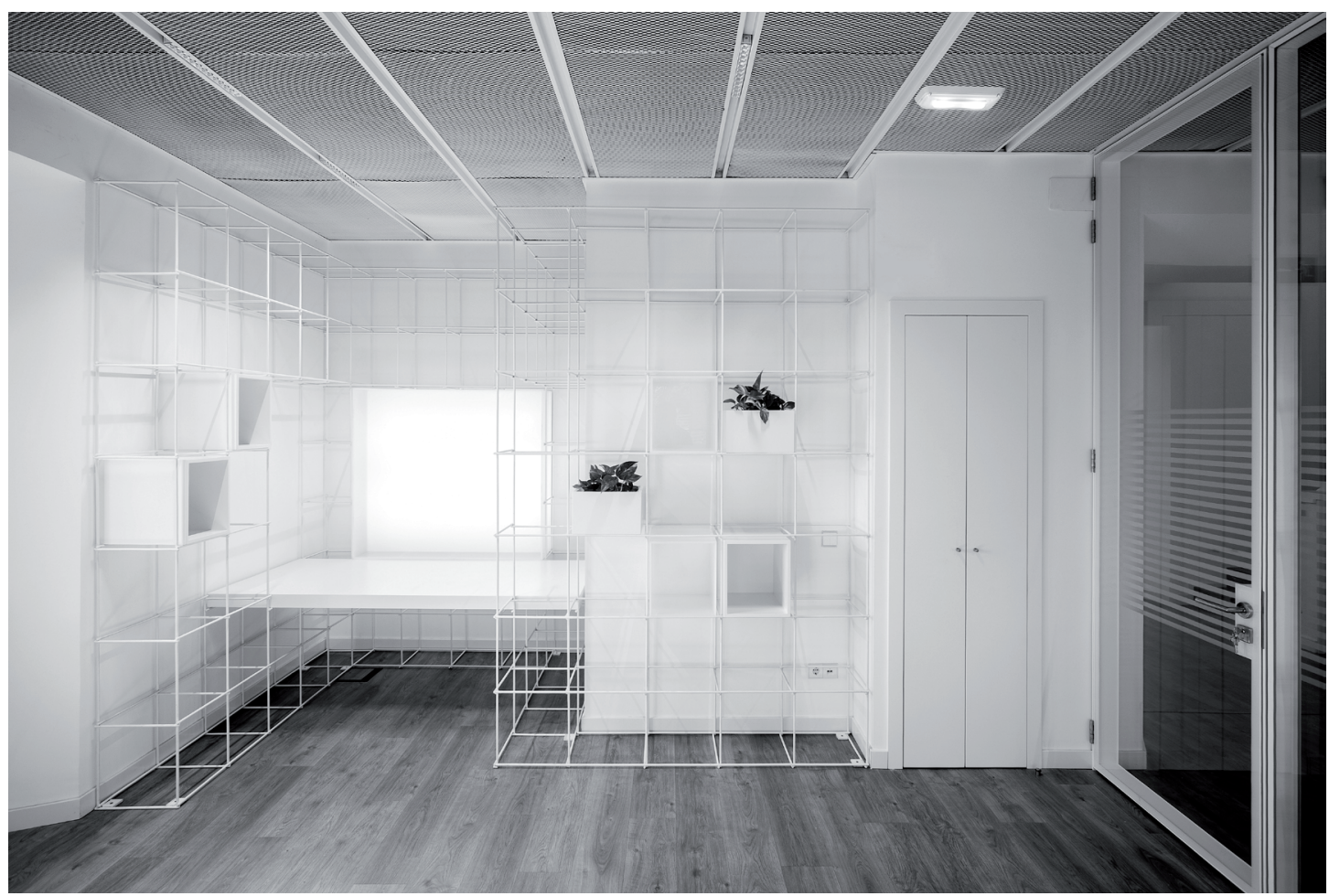

Figura 11. Detalle de oficina en planta segunda.

\section{- Planta Primera:}

Se mantienen intacta la distribución de los accesos, vestíbulos y zonas de comunicación vertical. Se realiza la demolición de la tabiquería de las dos oficinas simétricas que aparecen tras cruzar el vestíbulo. En esta planta se contempla la ubicación de una única oficina y dispondrá de un pequeño espacio de atención al público junto al acceso, una oficina de administración y una zona con seis puestos de trabajo vinculados a un espacio diáfano junto a la galería. Para la oficina de administración, más privada, se plantea una partición mediante mamparas desmontables de vidrio que permitan cierta flexibilidad en el futuro a la hora de adaptarse a nuevas composiciones organizativas.

\section{- Planta Segunda:}

Nuevamente se conserva la distribución de los baños y las zonas de comunicación, respetando la composición original de la planta. En este caso se propone la división en dos oficinas simétricas que disponen de un espacio común polivalente vinculado a la galería. La separación entre oficinas se realiza mediante particiones modulares de vidrio tipo mampara. El amueblamiento se apoya en su composición y construcción en la malla tridimensional que define el proyecto.

\section{- Planta Bajocubierta:}

Se mantiene la organización existente sin plantear variaciones en cuanto a su distribu- 
ción. El espacio principal con estructura vista de madera se convierte en una oficina diáfana con puestos de trabajo centrales y asociados a la composición que define el despiece de la estructura. Se propone la apertura de un hueco en la tabiquería que comunique visualmente los espacios de circulación con la oficina y mejoren la luminosidad de los espacios. Para ello se produce la demolición parcial de esta tabiquería y se realiza una nueva partición de placas de yeso laminado, cerrando la apertura del hueco mediante mamparas de vidrio. Los almacenes existentes mantienen su uso actual.

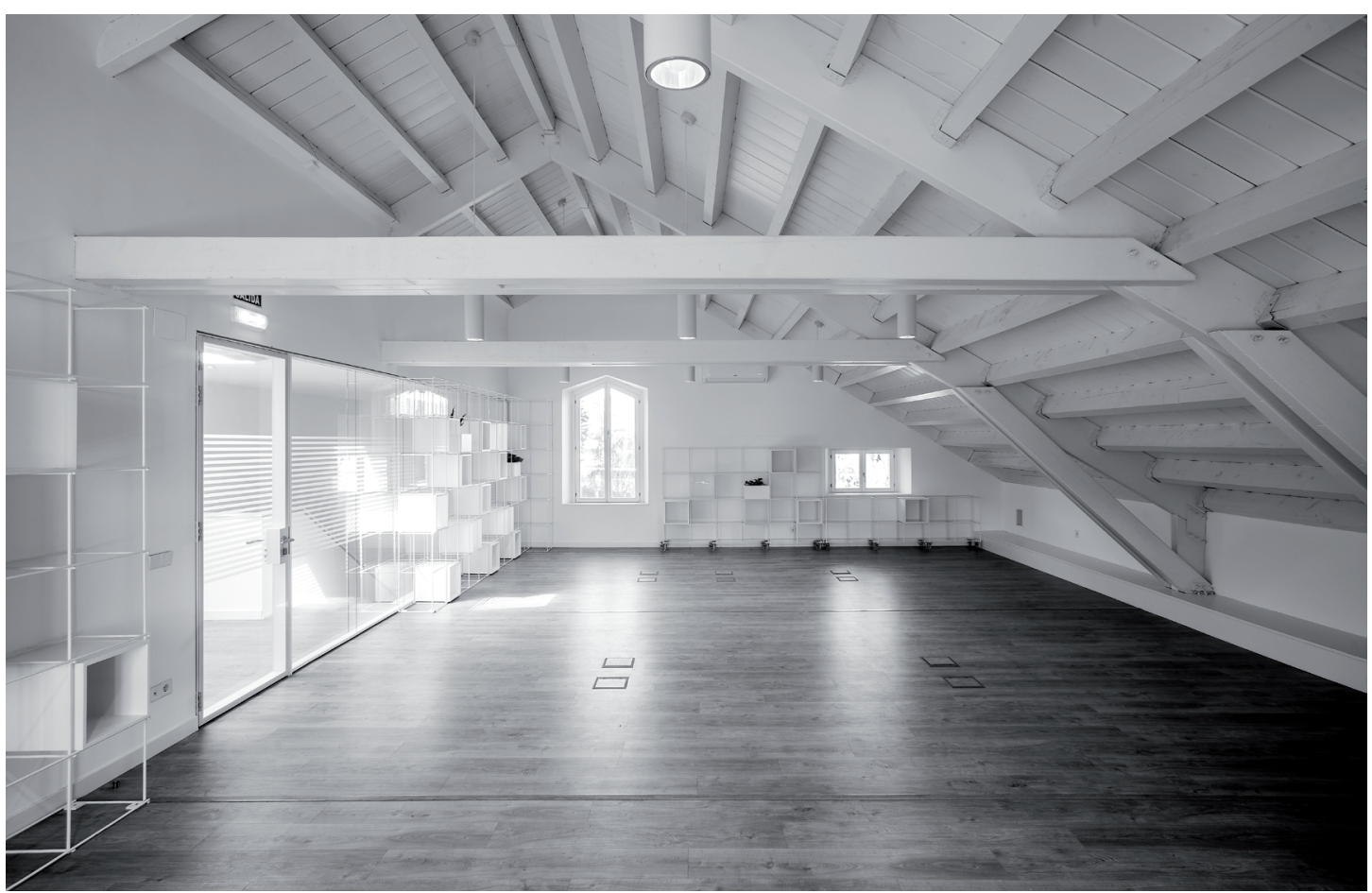

Figuras 12. Espacio bajocubierta.

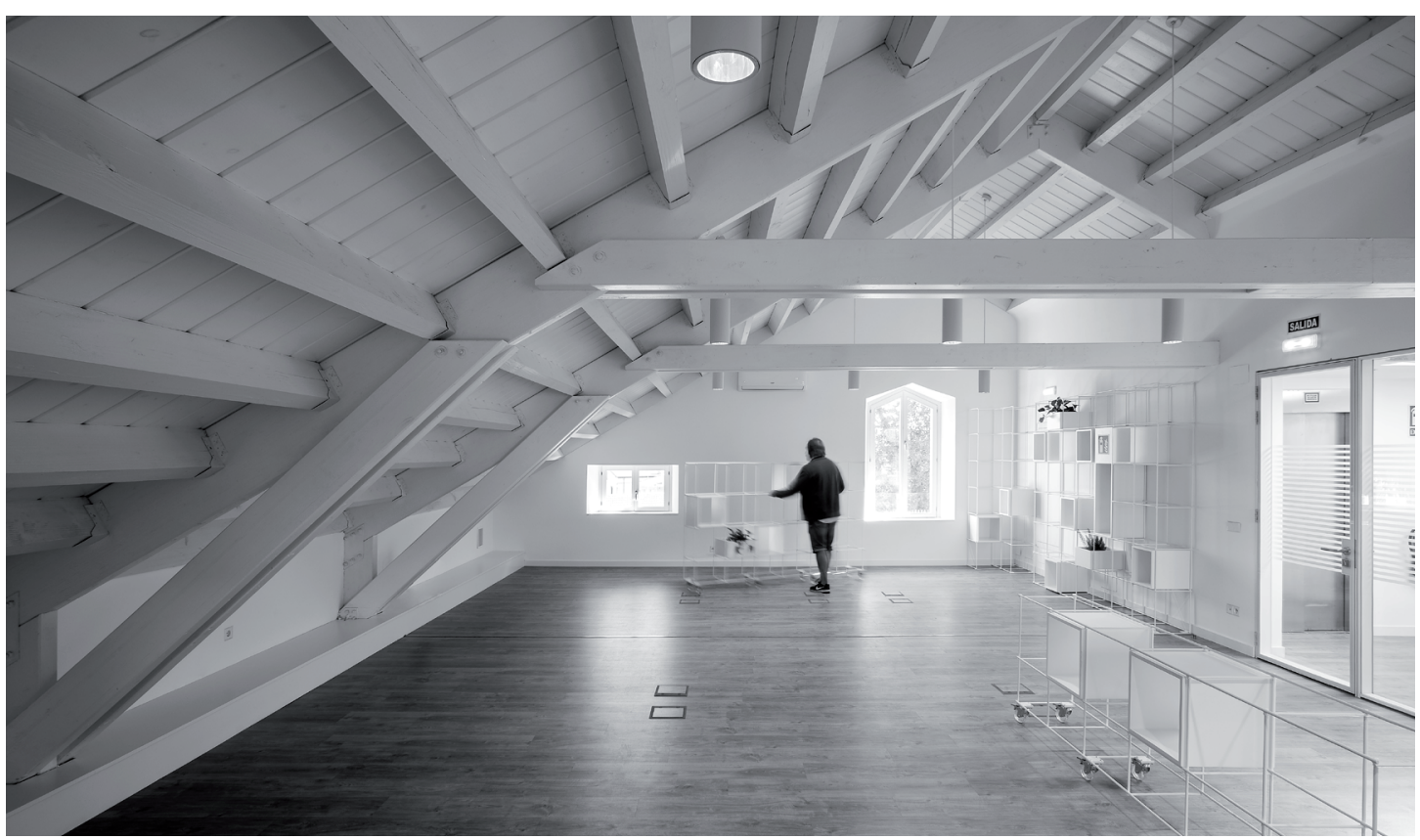

Figura 13. Espacio bajocubierta y detalle de muebles polivalentes. 